\title{
Ridge augmentation in implant dentistry
}

\author{
Young-Kyun Kim, DDS, PhD ${ }^{1,2,3}$, Jeong-Kui Ku, DDS, MMsc, FIBCOMS ${ }^{4,5}$

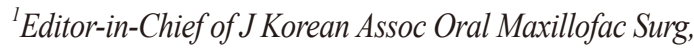 \\ ${ }^{2}$ Department of Oral and Maxillofacial Surgery, Section of Dentistry, Seoul National University Bundang Hospital, Seongnam, \\ ${ }^{3}$ Department of Dentistry \& Dental Research Institute, School of Dentistry, Seoul National University, Seoul, \\ ${ }^{4}$ Editorial Board of J Korean Assoc Oral Maxillofac Surg, \\ ${ }^{5}$ Department of Oral and Maxillofacial Surgery, Section of Dentistry, Armed Forces Capital Hospital, \\ Armed Forces Medical Command, Seongnam, Korea
}

\begin{abstract}
J Korean Assoc Oral Maxillofac Surg 2020;46:211-217)
In patients with insufficient bone height and width, the successful placement of dental implants is difficult with regards to maintaining an ideal pathway and avoiding important anatomical structures. Vertical and/or horizontal ridge augmentation may be necessary using various bone substitute materials and bone graft procedures. However, effective one-wall reconstruction has been challenging due to its poor blood supply and insufficient graft stability. In this paper, the authors summarize current evidence-based literature based on the author's clinical experience. Regarding bone substitutes, it is advantageous for clinicians to select the types of bone substitutes including autogenous bone. The most important consideration is to minimize complications through principle-based ridge augmentation surgery. Ridge augmentation should be decided with complete consent of the patients due to the possible disadvantages of surgery, complications, and unpredictable prognosis.
\end{abstract}

Key words: Ridge augmentation, Autogenous bone, Complications

[paper submitted 2020. 5. 18 / revised 2020. 5. 18 / accepted 2020. 5. 18]

\section{Introduction}

Various surgical techniques have been introduced to repair severe alveolar bone defects for dental implants. The clinician should aim to achieve successful results within the shortest period of time with appropriate techniques. The ideal technique should be simple, minimally invasive, and exhibit less risk of complications ${ }^{1}$. Ridge augmentation is very sensitive depending on the procedure type and operator's proficiency. However, not all of the augmented volume is regenerated into viable bone tissue. The survival of implants has been known to be more related with the condition and amount of remain-

\footnotetext{
Young-Kyun Kim

Department of Oral and Maxillofacial Surgery, Section of Dentistry, Seoul National University Bundang Hospital, 82 Gumi-ro 173beon-gil, Bundanggu, Seongnam 13620, Korea

TEL: +82-31-787-7541 FAX: +82-31-787-4068

E-mail:kyk0505@snubh.org

ORCID: https://orcid.org/0000-0002-7268-3870

(c) This is an open-access article distributed under the terms of the Creative Commons Attribution Non-Commercial License (http://creativecommons.org/ licenses/by-nc/4.0/), which permits unrestricted non-commercial use, distribution, and reproduction in any medium, provided the original work is properly cited.

Copyright (C) 2020 The Korean Association of Oral and Maxillofacial Surgeons. All rights reserved.
}

ing host bone rather than grafted bone volume.

Vertical and/or horizontal ridge augmentation is a technique to reconstruct a one-wall defect that receives blood supply mainly from the recipient bone and little from the above soft tissue. The soft tissue could potentially be damaged during the flap elevation process and blocked using a barrier membrane. Therefore, if a large amount of bone graft is performed vertically or horizontally, only some bone substitutes could be remodeled into viable bone tissue with the amount estimated to be within $3 \mathrm{~mm}$. The other areas would remain immature woven bone for a long period of time and be replaced by fibrous granulation tissue due to poor blood supply.(Fig. 1) Therefore, the healing process of ridge augmentation should be well-understood for successful dental implantation ${ }^{2}$.

Horizontal ridge augmentation has been known to have more stable results compared to vertical ridge augmentation. The reason could be theorized as the pressure from the coronal side being greater than that of the lateral side, with greater pressure leading to the loss of graft material and a greater frequency of wound dehiscence due to chronic stimulation by a temporary prosthesis and masticatory muscle functions. The authors report on a summary and discussion of available graft 

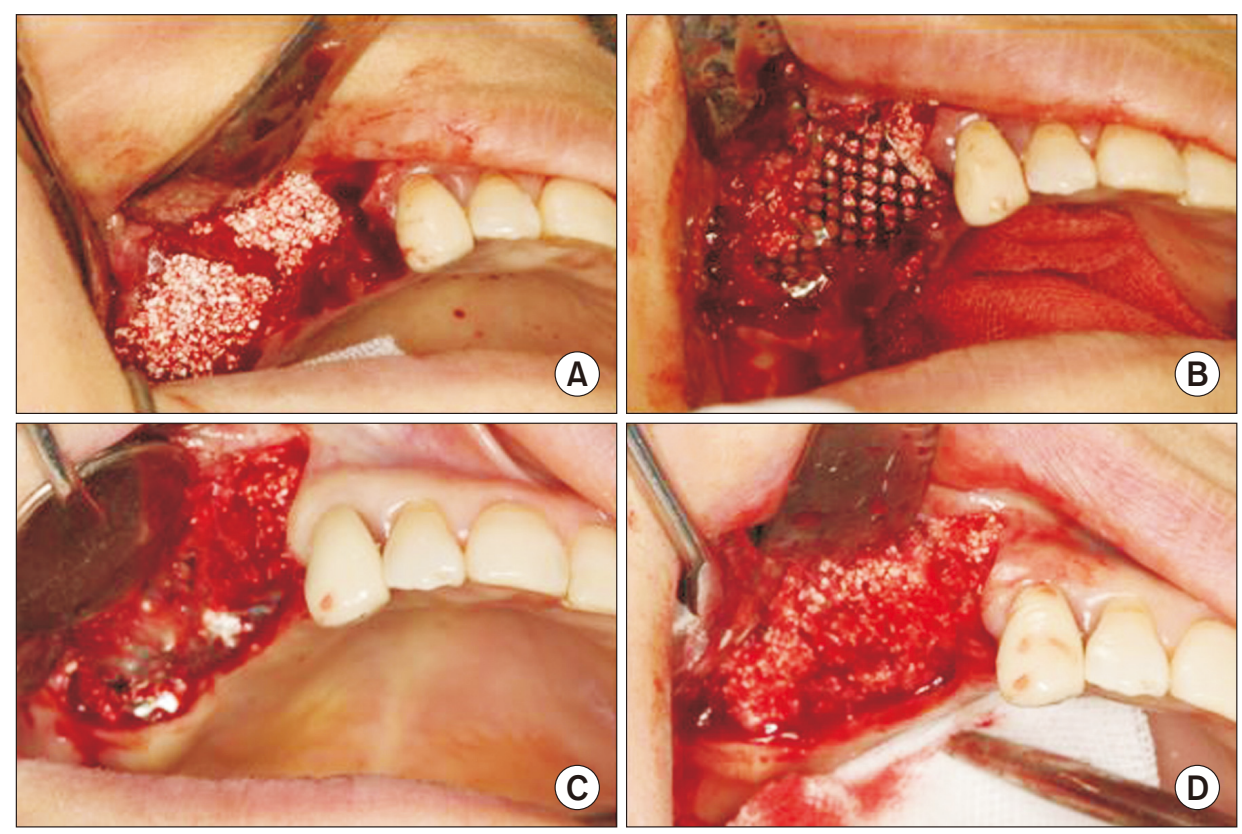

Fig. 1. Vertical ridge augmentation in a 53-year-old female. A. Allogenic and alIoplastic bone substitutes were grafted. B. The titanium mesh was covered and fixed. C. A mucoperiosteal flap was elevated to allow for dental implant placement at 4 months after bone grafting. D. After removal of the titanium mesh, immature woven bone was observed on the coronal side of the grafted bone. Young-Kyun Kim et al: Ridge augmentation in implant dentistry. J Korean Assoc Oral Maxillofac Surg 2020 materials, particulate vs block bone, types of ridge augmentations, complications, and periods of implant placement.

\section{Available Graft Material}

\section{Autogenous bone graft}

Autogenous bone has been considered the golden standard for bone grafts because of its osteogenic properties, infection resistance, and secondary healing potential with wound dehiscences. Unfortunately, it also has critical disadvantages such as inevitable additional surgeries, limited amount of harvested material, and the possibility of significant resorption. Therefore, many researchers recommend a mixture with other bone substitutes and covering with a resorbable barrier membrane ${ }^{3-9}$.

\section{Other bony substitutes}

For alternatives to autogenous bone, many studies have been conducted for allogenic, xenogenic, and alloplastic bone substitutes. However, few instances of clinical success have been reported in cases of using them alone for ridge augmentation $^{10}$. In particular, block-type bone substitutes were strongly recommended not to be used for bone grafts because of their poor results and high incidence of complications ${ }^{10-12}$.

\section{Bone growth factors}

Bone tissue engineering studies have been conducted to overcome several disadvantages of autogenous bone grafts. As a result, many studies have reported successful results with a mixture of an adequate scaffold and bone growth factors such as recombinant human platelet-derived growth factor (rhPDGF) and recombinant human bone morphogenetic protein-2 (rhBMP-2) ${ }^{13,14}$. Recently, several studies reported good bone healing after bone grafts with platelet rich plasma (PRP) or platelet rich fibrin (PRF) which could be obtained and prepared from the venous blood of patients ${ }^{15}$. Jeon et al. ${ }^{16}$ reported a $3.3 \mathrm{~mm}$ increase through vertical ridge augmentation using $\beta$-tricalcium phosphate with PRP.

\section{Barrier membranes}

There are no clear criteria for the use of barrier membranes, allowing clinicians to select membranes based on their preferences. Membranes could be effective for the stability of grafted bone in cases of particulate-type bone and an abundant amount of bone graft. Each resorbable and non-resorbable membrane has unique characteristics without a significant predominance. However, in one-wall defect reconstruction, titanium meshes have proven to be effective in stabilization of grafts due to its shape, rigidity, and ability to protect the underlying graft material ${ }^{17}$. 


\section{Particulate vs Block Type Autogenous Bone}

There has not been significantly different bone regeneration capacity between particulate and block type autogenous bone. With regards to clinical situations, most cases use a mixture of particulate and block type autogenous bone with other additional bone substitutes ${ }^{18,19}$

\section{Particulate autogenous bone graft}

The sandwich technique was introduced in the following order where autogenous bone is grafted in the contact area with the implant, a demineralized freeze-dried allogenic bone
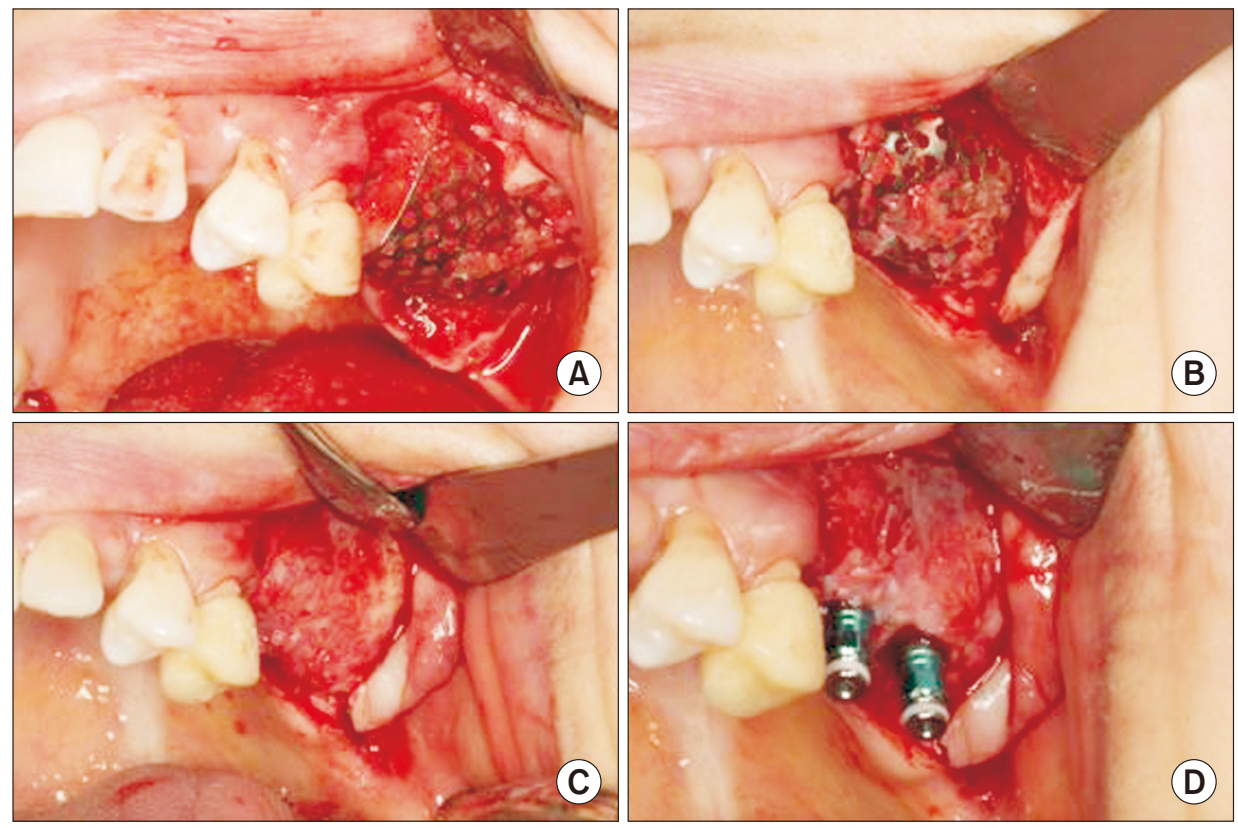

Fig. 2. Vertical and horizontal ridge augmentation in a 36-year-old female. A. Ridge augmentation was performed with particulate autogenous bone and allogenic bone and covered with a titanium mesh. B. Intraoral photographs at 4 months after the augmentation. C. The titanium mesh was removed. D. The dental implant was placed at 4 months after the augmentation.

Young-Kyun Kim et al: Ridge augmentation in implant dentistry. J Korean Assoc Oral Maxillofac Surg 2020
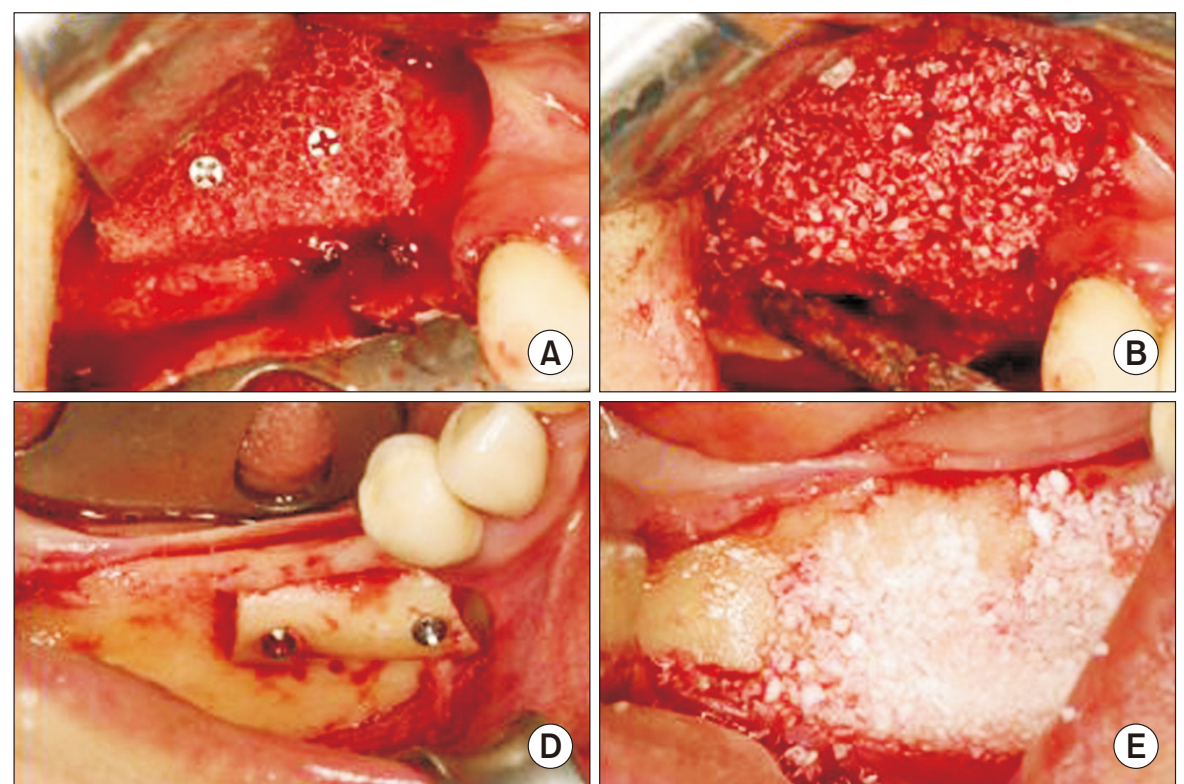
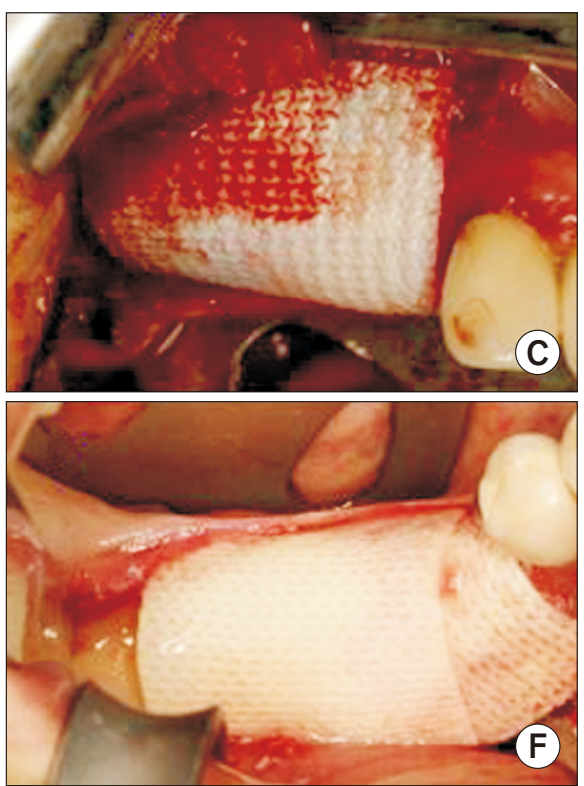

Fig. 3. Horizontal ridge augmentation using a block type bone graft. An allogenic bone block was used on the upper site, while an autogenous bone block was used on the lower site. A. The allogenic bone block was fixed with titanium screws in a 68-year-old male. B. BioOss (Geistlich, Switzerland) was packed surrounding the allogenic bone. C. An Ossix membrane (OraPharma, USA) was used to cover the surgical site. D. An autogenous ramus bone block was fixed with titanium screws in a 65-year-old female. E. Bio-Oss was packed surrounding the bone block. F. An Ossix membrane was used to cover the surgical site.

Young-Kyun Kim et al: Ridge augmentation in implant dentistry. J Korean Assoc Oral Maxillofac Surg 2020 
or bovine hydroxyapatite bone is grafted over the autogenous graft, and a collagen membrane covers the graft site ${ }^{20}$. In clinical practice, many bone augmentation procedures have been performed with similar principles to the sandwich technique. Some surgeons prefer to cover grafts with non-resorbable membranes such as titanium meshes. This method has been known to be effective for vertical and horizontal augmentation results with the stable mechanical properties of the membrane $^{21}$.(Fig. 2)

\section{Block autogenous bone graft}

Block type autogenous bone, harvested mainly in intraoral sites, is fixed with screws after intimate adaptation to the recipient surface. Particulate autogenous bone or other particulate bone substitutes are then packed in the surrounding empty space. A resorbable membrane is generally used as a cover to provide additional stability to the grafts ${ }^{22-24}$.(Fig. 3)

\section{Types of Ridge Augmentation Procedures}

Although divided into horizontal or vertical ridge augmentation, both methods are often performed simultaneously.

\section{Horizontal ridge augmentation (Fig. 4)}

Recently in implant dentistry, minimally invasive horizontal ridge augmentations are widely performed using particulate or block autogenous bone grafts with ridge splitting or ridge expansion combined with guided bone regeneration
(GBR). Each procedure has clear advantages and disadvantages with no significantly different clinical results. Surgeon should select adequate techniques based on evidence and principles. Horizontal ridge augmentation has been known to exhibit more predictable outcomes and higher success rates compared to vertical ridge augmentation. The reconstruction amount has an average 3 to $4 \mathrm{~mm}$ target in horizontal ridge augmentations $^{25}$.

\section{Vertical ridge augmentation (Fig. 5)}

For the reconstruction of one-wall defects, onlay grafts are generally performed as GBR with particulate or block type autogenous bone grafts. However, onlay grafts have been reported to have high complication risks such as wound dehiscence, infection, bone resorption, and graft failure ${ }^{25}$. Alternative techniques such as interpositional bone grafts (sandwich osteotomy) and alveolar bone distraction have been used to avoid these complications. In particular, the sandwich osteotomy is known to have a successful prognosis because of its optimal soft tissue coverage and blood circulation. The vertical portion is positioned on cortical bone, which has the advantage of enduring occlusal loads and absorption. The average increase in onlay grafts is 3 to $4 \mathrm{~mm}$, while sandwich osteotomies are reported to exhibit an increase of approximately 5 to $7 \mathrm{~mm}$. Nevertheless, some cases cannot undergo sandwich osteotomies due to the limitation of anatomical structures such as the inferior alveolar canal and maxillary sinus. On the other hand, a technique (supraplant) was introduced to increase vertical bone height simultaneously with
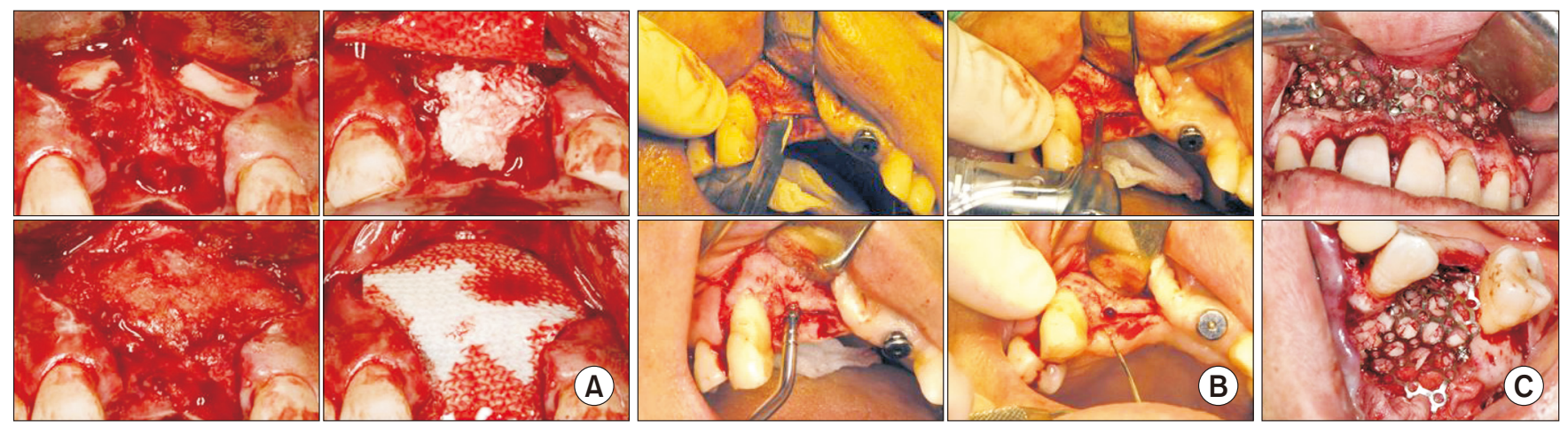

Fig. 4. Various techniques for horizontal ridge augmentation. A. Maxillary anterior horizontal ridge augmentation called 'sandwich bone augmentation.' Two autogenous bone blocks were grafted on the labial aspect, freeze dried allogenic bone was grafted above the autogenous bone, and a demineralized allogenic bone matrix was implanted over the grafts. Wound closure was performed after covering the resorbable collagen membrane. B. Maxillary anterior ridge splitting and ridge expansion. The thin ridge crest was split with a \#15 surgical blade and chisel. Initial implant drilling was performed in the resulting space. Horizontal ridge expansion was performed by sequentially applying the osteotome or screw expander from small to thick in the drilling hole. The amount of expansion could be increased by using additional bone graft materials. C. The autogenous particulate bone graft was fixed by a titanium mesh.

Young-Kyun Kim et al: Ridge augmentation in implant dentistry. JKorean Assoc Oral Maxillofac Surg 2020 

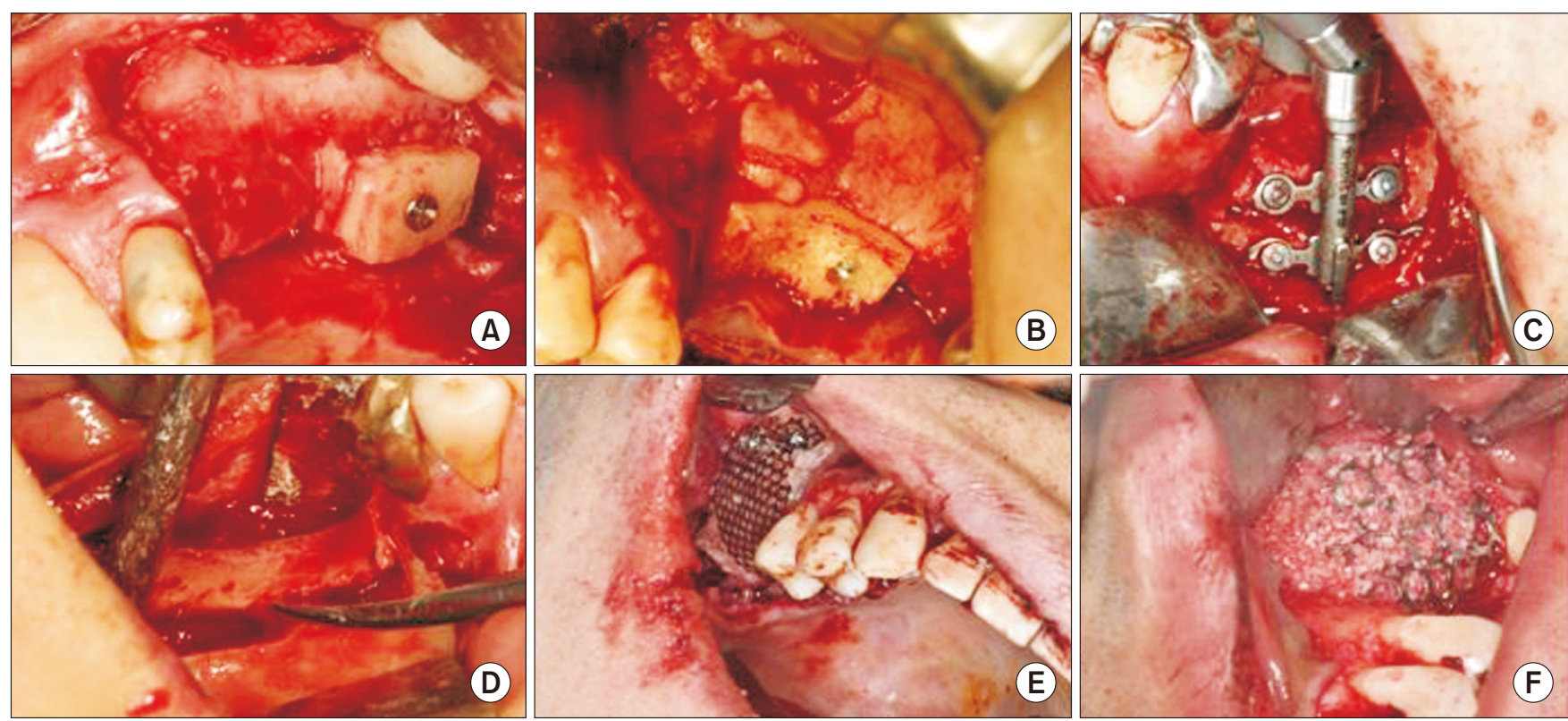

Fig. 5. Various techniques for vertical ridge augmentation. A. An autogenous bone block was grafted on the alveolar crest and fixed with titanium screws. B. An autogenous bone block onlay graft was placed simultaneously with sinus bone grafting. C. Distraction osteogenesis was performed vertically on alveolar bone. D. Vertical ridge augmentation was performed with an interpositional bone graft. E, F. Vertical ridge augmentation using particulate bone and a titanium mesh. The autogenous particulate bone graft was fixed by a titanium mesh. Young-Kyun Kim et al: Ridge augmentation in implant dentistry. J Korean Assoc Oral Maxillofac Surg 2020
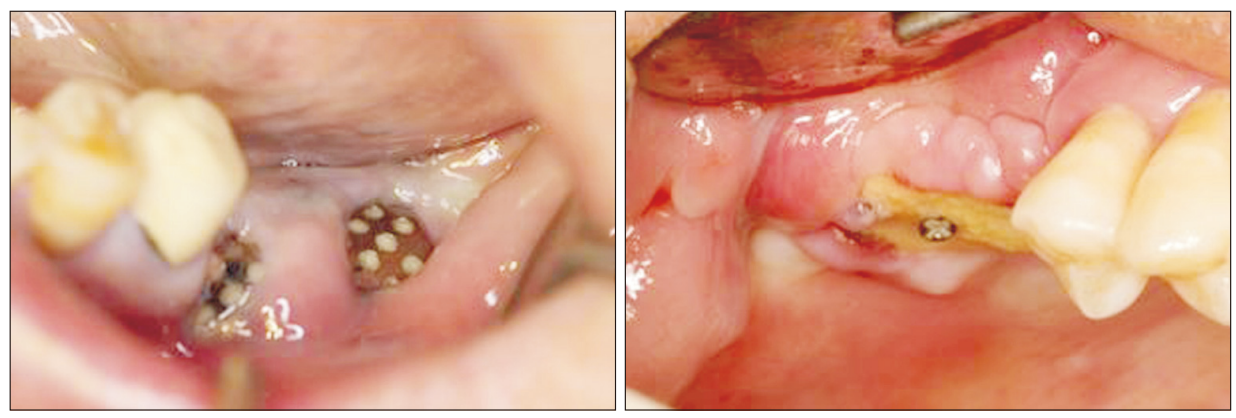

Fig. 6. Wound dehiscence and graft material exposure most frequently occurred, often progressing to postoperative infections, graft loss, and total failure.

Young-Kyun Kim et al: Ridge augmentation in implant dentistry. J Korean Assoc Oral Maxillofac Surg 2020 implantation on the top of the alveolar crest. Several reports have shown acceptable results, but long-term clinical results have been rarely reported. With regards to clinical practice with the supraplant technique, the incidence of complications has been high with most of the surrounding grafted bone exhibiting resorption ${ }^{26-29}$.

\section{Complications}

Ridge augmentation has a high risk of complications such as wound dehiscence, exposure of the grafts, infection, failure of integration, and late bone resorption. These complications could lead to the complete loss of the entire graft. Therefore, the surgeon must comply with the following precautions $^{16,25,30-32}$.(Fig. 6)
1) Adequate blood supply to the graft

2) Adequate modelling and fixation of the block

3) Covering of the bone block with slowly resorbable xenografts

4) Releasing incisions for a tension-free flap

5) Avoidance of load or compression on the reconstructed area with removable prostheses

6) Sufficient healing period to allow for the successful integration of the grafts without simultaneous dental implant placement

7) Avoidance of over-contouring with block type autogenous bone grafts that could cause wound dehiscences

\section{Implant Placement Timing}

If initial stability of the implant can be obtained, the im- 
plant could potentially be placed simultaneously with the ridge augmentation. However, there is a high risk of complications such as wound dehiscence, infection, and graft failure. Ridge augmentations with delayed implant placement is recommended for stable and successful results. Patients should be fully informed that the total treatment period could require a long period of time, and the surgery must be performed with careful operative consent. With autogenous bone grafts, implants can be placed after 4 to 6 months. Block type autogenous bone grafts could require a longer healing period than particulate autogenous bone grafts. Block bone separation from implants was often reported in cases of insufficient healing time. The healing period should be longer if the bone graft materials include allogenic, xenogenic, and alloplastic bone substitutes without autogenous bone. The authors advise clinicians to provide an adequate healing period of at least 12 months ${ }^{33}$.

\section{Summary of Ridge Augmentation in Implant Dentistry}

1. Vertical or horizontal ridge augmentation in one-wall defects remains challenging with a high risk of complications.

2. To maximize the effects of bone grafts, autogenous bone should be primarily considered with other bone substitutes added with covering barrier membranes and primary wound closure.

3. Sufficient healing time should be allowed to result in successful dental implant placement. A 4- to 6-month healing period is recommended for autogenous bone and at least 12 months without autogenous bone.

4. For successful results, the clinician should follow the principles of bone graft procedures and understand the characteristics of each surgical technique and bone substitute.

5. Ridge augmentation should be performed after obtaining informed consent with a detailed explanation of other alternative methods.

\section{ORCID}

Young-Kyun Kim, https://orcid.org/0000-0002-7268-3870

Jeong-Kui Ku, https://orcid.org/0000-0003-1192-7066

\section{Authors' Contributions}

Y.K.K. participated in the literature review and wrote the primary manuscript. J.K.K. participated in the literature re- view and wrote the final manuscript. Y.K.K. and J.K.K. provided the clinical photographs.

\section{Conflict of Interest}

No potential conflict of interest relevant to this article was reported.

\section{References}

1. Chiapasco M, Casentini P, Zaniboni M. Bone augmentation procedures in implant dentistry. Int J Oral Maxillofac Implants 2009;24 Suppl:237-59.

2. Aghaloo TL, Moy PK. Which hard tissue augmentation techniques are the most successful in furnishing bony support for implant placement? Int J Oral Maxillofac Implants 2007;22 Suppl:49-70.

3. Chiapasco M, Tommasato G, Palombo D, Scarnò D, Zaniboni M, Del Fabbro M. Dental implants placed in severely atrophic jaws reconstructed with autogenous calvarium, bovine bone mineral, and collagen membranes: a 3- to 19-year retrospective follow-up study. Clin Oral Implants Res 2018;29:725-40.

4. Simion M, Fontana F, Rasperini G, Maiorana C. Vertical ridge augmentation by expanded-polytetrafluoroethylene membrane and a combination of intraoral autogenous bone graft and deproteinized anorganic bovine bone (Bio Oss). Clin Oral Implants Res 2007;18:620-9.

5. Chiapasco M, Zaniboni M, Rimondini L. Autogenous onlay bone grafts vs. alveolar distraction osteogenesis for the correction of vertically deficient edentulous ridges: a 2-4-year prospective study on humans. Clin Oral Implants Res 2007;18:432-40.

6. Restoy-Lozano A, Dominguez-Mompell JL, Infante-Cossio P, Lara-Chao J, Espin-Galvez F, Lopez-Pizarro V. Reconstruction of mandibular vertical defects for dental implants with autogenous bone block grafts using a tunnel approach: clinical study of 50 cases. Int J Oral Maxillofac Surg 2015;44:1416-22.

7. Park YJ, Choi GH, Jang JR, Jung SG, Han MS, Yu MG, et al. The effect of new bone formation of onlay bone graft using various graft materials with a titanium cap on the rabbit calvarium. J Korean Assoc Maxillofac Plast Reconstr Surg 2009;31:469-77.

8. Roccuzzo M, Ramieri G, Bunino M, Berrone S. Autogenous bone graft alone or associated with titanium mesh for vertical alveolar ridge augmentation: a controlled clinical trial. Clin Oral Implants Res 2007;18:286-94.

9. Draenert FG, Huetzen D, Neff A, Mueller WE. Vertical bone augmentation procedures: basics and techniques in dental implantology . J Biomed Mater Res A 2014;102:1605-13.

10. Schliephake H, van den Berghe P, Neukam FW. Osseointegration of titanium fixtures in onlay grafting procedures with autogenous bone and hydroxylapatite. An experimental histometric study. Clin Oral Implants Res 1991;2:56-61.

11. Waasdorp J, Reynolds MA. Allogeneic bone onlay grafts for alveolar ridge augmentation: a systematic review. Int J Oral Maxillofac Implants 2010;25:525-31.

12. Draenert FG, Kämmerer PW, Berthold M, Neff A. Complications with allogeneic, cancellous bone blocks in vertical alveolar ridge augmentation: prospective clinical case study and review of the literature. Oral Surg Oral Med Oral Pathol Oral Radiol 2016;122:e3143.

13. Hahn J. 8-year onlay bone graft and ridge augmentation with PepGen P-15: a clinical and radiographic case study. Implant Dent 2004;13:228-31.

14. Byun HY, Wang HL. Sandwich bone augmentation using recombinant human platelet-derived growth factor and beta-tricalcium 
phosphate alloplast: case report. Int J Periodontics Restorative Dent 2008;28:83-7.

15. Hartlev J, Spin-Neto R, Schou S, Isidor F, Nørholt SE. Cone beam computed tomography evaluation of staged lateral ridge augmentation using platelet-rich fibrin or resorbable collagen membranes in a randomized controlled clinical trial. Clin Oral Implants Res 2019;30:277-84.

16. Jeon IS, Heo MS, Han KH, Kim JH. Vertical ridge augmentation with simultaneous implant placement using $\beta$-TCP and PRP: a report of two cases. J Oral Maxillofac Surg Med Pathol 2013;25:22631.

17. Molly L, Quirynen M, Michiels K, van Steenberghe D. Comparison between jaw bone augmentation by means of a stiff occlusive titanium membrane or an autologous hip graft: a retrospective clinical assessment. Clin Oral Implants Res 2006;17:481-7.

18. Oh SH. Vertical alveolar bone augmentation using thin block and chip bone graft technique: case report. J Korean Assoc Maxillofac Plast Reconstr Surg 2008;30:108-13.

19. Merli M, Migani M, Esposito M. Vertical ridge augmentation with autogenous bone grafts: resorbable barriers supported by ostheosynthesis plates versus titanium-reinforced barriers. A preliminary report of a blinded, randomized controlled clinical trial. Int J Oral Maxillofac Implants 2007;22:373-82.

20. Wang HL, Misch C, Neiva RF. "Sandwich" bone augmentation technique: rationale and report of pilot cases. Int J Periodontics Restorative Dent 2004;24:232-45.

21. Longoni S, Sartori M, Apruzzese D, Baldoni M. Preliminary clinical and histologic evaluation of a bilateral 3-dimensional reconstruction in an atrophic mandible: a case report. Int J Oral Maxillofac Implants 2007;22:478-83.

22. Proussaefs P, Lozada J. The use of intraorally harvested autogenous block grafts for vertical alveolar ridge augmentation: a human study. Int J Periodontics Restorative Dent 2005;25:351-63.

23. Carini F, Longoni S, Amosso E, Paleari J, Carini S, Porcaro G. Bone augmentation with TiMesh. autologous bone versus autologous bone and bone substitutes. A systematic review. Ann Stomatol (Roma) 2014;5(Suppl 2 to No 2):27-36.

24. von Arx T, Buser D. Horizontal ridge augmentation using autogenous block grafts and the guided bone regeneration technique with collagen membranes: a clinical study with 42 patients. Clin Oral Implants Res 2006;17:359-66.

25. Hellem S, Astrand P, Stenström B, Engquist B, Bengtsson M, Dahlgren S. Implant treatment in combination with lateral augmentation of the alveolar process: a 3-year prospective study. Clin Implant Dent Relat Res 2003;5:233-40.

26. Schmid J, Hämmerle CH, Stich H, Lang NP. Supraplant, a novel implant system based on the principle of guided bone generation. A preliminary study in the rabbit. Clin Oral Implants Res 1991;2:199-202

27. Roos-Jansåker AM, Franke-Stenport V, Renvert S, Albrektsson T, Claffey N. Dog model for study of supracrestal bone apposition around partially inserted implants. Clin Oral Implants Res 2002;13:455-9.

28. Stenport VF, Roos-Jansåker AM, Renvert S, Kuboki Y, Irwin C, Albrektsson T, et al. Failure to induce supracrestal bone growth between and around partially inserted titanium implants using bone morphogenetic protein (BMP): an experimental study in dogs. Clin Oral Implants Res 2003;14:219-25.

29. Simion M, Dahlin C, Rocchietta I, Stavropoulos A, Sanchez R, Karring $\mathrm{T}$. Vertical ridge augmentation with guided bone regeneration in association with dental implants: an experimental study in dogs. Clin Oral Implants Res 2007;18:86-94.

30. Kloss FR, Offermanns V, Kloss-Brandstätter A. CEComparison of allogeneic and autogenous bone grafts for augmentation of alveolar ridge defects-A 12-month retrospective radiographic evaluation. Clin Oral Implants Res 2018;29:1163-75.

31. Urban I, Traxler H, Romero-Bustillos M, Farkasdi S, Bartee B, Baksa G, et al. Effectiveness of two different lingual flap advancing techniques for vertical bone augmentation in the posterior mandible: a comparative, split-mouth cadaver study. Int J Periodontics Restorative Dent 2018;38:35-40.

32. Shet UK, Cho MS, Hur JW, Oh CJ, Chung K, Park HJ, et al. Evaluation of augmented alveolar bone and dental implant after autogenous onlay block bone graft. J Korean Dent Assoc 2012;50:32938.

33. Oh JK, Choi BJ, Lee BS. The histologic study of bone healing after horizontal ridge augmentation using auto block bone graft. J Korean Assoc Maxillofac Plast Reconstr Surg 2009;31:207-15.

How to cite this article: Kim YK, Ku JK. Ridge augmentation in implant dentistry. J Korean Assoc Oral Maxillofac Surg 2020;46:211-217. https://doi.org/10.5125/jkaoms.2020.46.3.211 